\title{
Una aproximación a LABoral. Centro de Arte y Creación Industrial (2007-2011) desde la teoría y la praxis de José Luis Brea*
}

\section{An approach to LABoral. Centro de Arte y Creación Industrial (2007-2011) from the theory and praxis of José Luis Brea}

\author{
Miguel Vega Manrique \\ Universidad Autónoma de Madrid
}

Fecha de recepción: 1 de junio de 2020

Fecha de aceptación: 27 de febrero de 2021

\author{
Anuario del Departamento de Historia y Teoría del Arte \\ vol. 33, 2021, pp. 119-134 \\ ISSN: 1130-5517, eISSN: 2530-3562 \\ https://doi.org/10.15366/anuario2021.33.006
}

\begin{abstract}
RESUMEN
La hipótesis de la que partimos es que ciertas tesis formuladas por José Luis Brea sobre el estatuto de las prácticas artísticas en la era del mundo-Internet, acompañadas de su labor artística y curatorial en la red, podrían verse continuadas y ampliadas con la puesta en marcha y consolidación de LABoral. Centro de Arte y Creación Industrial de Gijón. Creemos que el programa del centro asturiano, dedicado íntegramente al arte, la ciencia, la tecnología y la innovación, materializa una parte significativa de las concepciones que sostenía Brea para un mundo inmerso en la digitalización de los procesos de producción. En el presente artículo intentaremos poner de manifiesto la transición del net art a la contemporaneidad de las prácticas artísticas; la posible influencia de Brea en dicho proyecto institucional, que fragua su primera directora Rosina Gómez-Baeza; y la conexión existente y apenas comentada entre ambos actores del mundo del arte en el estado español.
\end{abstract}

\begin{abstract}
The theoretical-critical work of José Luis Brea in relation to artistic practices and the capitalist power system, as well as his artistic and curatorial work according to the mutations of the context that surrounded him, connect with the launch and consolidation of LABoral. Centro de Arte y Creación Industrial de Gijón. The Asturian center's program, dedicated to art, science, technology and innovation, exemplifies the materialization of a significant part of Brea's theories for a world immersed in the digitization of production processes. In this article we will try to highlight the transition from net art to contemporary artistic practices; the influence of Brea in this institutional project, forged by Rosina Gómez-Baeza; and the existing and hardly commented connection between both actors of the art world in the Spanish state.
\end{abstract}

\footnotetext{
* El presente artículo forma parte de la investigación realizada en "José Luis Brea: teoría y praxis en la era del mundo-Internet. De la cultura RAM y el capitalismo cultural electrónico a las prácticas artísticas en LABoral Centro de Arte y Creación Industrial (2007-2011)", Trabajo Fin de Máster, Madrid, Universidad Autónoma de Madrid - Universidad Complutense de Madrid - Museo Nacional Centro de Arte Reina Sofía, 2018. Agradezco a Jesús Carrillo haberme invitado a pensar sobre Brea y haberme traído hasta aquí; al tutor, Fernando Castro, su consejo y seguimiento; a Olga Fernández y Juan Albarrán sus precisas indicaciones. Un especial agradecimiento para Rosina Gómez-Baeza, quien generosamente me prestó todo el archivo de LABoral y colaboró concediéndome una extensa entrevista. Otros nombres que no puedo pasar por alto son José Maldonado y Juan Martín Prada, siempre dispuestos a esclarecer cualquier duda sobre la trayectoria de su compañero y amigo José Luis Brea.
} 


\section{PALABRAS CLAVE}

LABoral. José Luis Brea. Cultura RAM. Nuevos medios.

\section{KEY WORDS}

LABoral. José Luis Brea. RAM culture. New media.

\section{Introducción}

Cuando tiene lugar una síntesis entre teoría y praxis, pensamiento y acción, discurso y producción artística, "ni el texto se somete a la dictadura de las obras, ni mucho menos estas a las del texto". Así entendía José Luis Brea, desde el foro de la revista Arena a finales de los años ochenta, su incursión en el campo de la estética del arte contemporáneo, así como de la práctica artística y curatorial. Ambos quehaceres fueron indisociables del instinto teórico-crítico que impulsaba su actividad dentro del contexto del arte español hasta sus últimos días, hacia el fin de la primera década del siglo XXI. Ante la expansión de la World Wide Web y su ineludible impacto en la redefinición de las telecomunicaciones, Brea decide sumergirse in situ en el pensamiento de las metamorfosis en curso que transforman progresivamente los paradigmas relacionales. No hay que olvidar que la teoría, tal como Brea la concibe, es una práctica en sí misma. Por ello, el dualismo entre teoría y praxis que planteamos desde un inicio, en sentido genérico, no es más que un recurso narrativo con el objetivo de diferenciar la práctica propiamente teórica, de la curatorial y artística; a esta última, la denominaremos praxis.

La primera incursión verificable de Brea en la red tiene lugar en un momento tan temprano como lo es el año 1997. Su presencia se hará plausible a través de plataformas online, véase el caso concreto de Aleph (1997-2002), o mediante la participación en eventos que poco a poco abren paso al mundo digital, como por ejemplo las ferias de ARCO dedicadas al arte electrónico (1997-1998-1999). Todo ello sitúa la figura de Brea muy próxima a la vanguardia tecnológica del cambio de siglo. Y es entonces cuando decimos que la aludida presencia de Brea en los parajes digitales, sin duda acorde al influjo centroeuropeo que inoculaba sus últimas tendencias sobre cultura electrónica e informatización del saber al contexto español, continúa y prolonga semejantes inquietudes experimentales en el medio cibernético, por entonces en boga debido a sus potenciales emancipadores y espejismos que hacían entrever otras alternativas comunitarias para el nuevo milenio.

Los profundos desplazamientos que operan estos soportes en el terreno de las prácticas artísticas orientan hacia el futuro las discusiones acerca del estatuto de la obra de arte y su reproductibilidad digital, problematizan las nociones de autoría, distribución, exhibición y almacenamiento, a la vez que erosionan los cimientos del proceso creativo. Manuel Castells intenta condensar, a finales de los años noventa, la efervescencia de estas contemporáneas y (habida cuenta de la contingencia brevemente esbozada) esperanzadoras transformaciones en una gruesa trilogía de libros englobada bajo el título La era de la información: economía, sociedad y cultura.

Será a partir de entonces cuando podamos establecer un vínculo de unión entre Brea y otra de las personalidades más destacadas de la institución-arte en el contexto del estado español: Rosina Gómez-Baeza. Ambos, desde posiciones aparentemente distantes, antagónicas incluso, podría decirse, han desarrollado aportaciones de considerable relevancia en las últimas décadas para la historia del arte actual. Desde el vacío casi absoluto en lo referente a sus trayectorias procederemos a dilucidar la conjunción que aglutina Internet, el comisariado y las prácticas artísticas en torno al poco comentado nexo entre estas dos figuras y sus muy distintos grados de implicación en un proyecto como LABoral. Centro de Arte y Creación In-

\footnotetext{
1 José Luis Brea, “Antes y después del entusiasmo”, Arena 3 (1989): 26.
} 
dustrial de Gijón (2007-2011). Para ello, trataremos de conectar diferentes acontecimientos, artefactos y personalidades con el ya aludido potencial del arte electrónico, desde el surgimiento del net art hasta su ocaso, tras la eclosión de la web 2.0, y sus posteriores proyecciones institucionales.

¿En qué momento podríamos señalar el punto de encuentro entre José Luis Brea y Rosina GómezBaeza? ¿Qué papel jugaron dentro del panorama del arte y los nuevos medios en el contexto español? ¿Representa LABoral una posible síntesis entre teoría y praxis afín a los postulados de una parte significativa de la producción de Brea? Con conocimiento de causa acerca de las problemáticas para ofrecer respuestas concluyentes y el delgado margen de maniobra que dejaron estas dos singulares trayectorias entre sí, nos serviremos de publicaciones, entrevistas, exposiciones, seminarios y procesos concretos de institucionalización para tratar de elaborar un tejido narrativo donde confluyan las hipótesis que planteamos.

Asimismo, el presente trabajo tiene como principal punto de referencia los textos recogidos en $\mathrm{cul}$ tura_RAM. Mutaciones de la cultura en la era de su distribución electrónica (2007), por considerarlos más próximos a los siguientes objetivos: vincular la teoría y la praxis en torno a la cultura digital en lo referente a la figura de Brea; presentar LABoral como caso de estudio a través de la vinculación entre las derivas profesionales de Brea y Gómez-Baeza, sus intereses conjuntos respecto al arte y los nuevos medios, y el (a nuestro parecer) hipotético influjo del pensamiento del primero en el centro asturiano. No tendrán cabida los presupuestos teóricos de Brea referentes a los estudios visuales, que ocuparon el último periodo de la actividad del autor, por ser este un amplio terreno de estudio que desbordaría los objetivos planteados.

A la hora de abordar la actividad de Brea en el ámbito de las prácticas artísticas desde un enfoque histórico, la metodología de investigación ha consistido, principalmente, en entrevistas con teóricos, gestoras y artistas (Gómez-Baeza, Juan Martín Prada, Ricardo Echevarría, Fernando Broncano, José Maldonado...) vinculados con Brea durante un periodo concreto: desde los noventa, con la incursión del arte en la red, hasta el año 2011, en el cual finaliza la primera etapa de LABoral, que pone en marcha y dirige durante estos años Gómez-Baeza. Por razones, creemos, más que justificadas, decidimos incluir el testimonio de esta última recogido en una entrevista inédita que concede para el presente artículo y confirma el nexo con Brea, más allá de otras referencias colaterales documentadas en el ámbito instuticional. Con ella, además, se pone de manifiesto la influencia de este último en la articulación teórica y material del centro de arte contemporáneo que aún sigue en funcionamiento en Asturias.

\section{José Luis Brea y las prácticas artísticas en la red: de Arco Electrónico (1997-98-99) a LABoral. Centro de Arte y Creación Industrial (2007-2011)}

Un paradójico suceso que tiene lugar días antes de que toque a su fin la Documenta X de Kassel (21 de junio-28 de septiembre, 1997), pionera por su magnitud en internacionalizar los usos artísticos de las nuevas tecnologías, ilustra la ambivalente y contradictoria situación que le tocaba vivir al arte en los albores del mundo-Internet. Esta acción estuvo focalizada en el espacio Hybrid Work Space, el cual mostraba las precoces manifestaciones de cyberfeminismo y activismo digital. Simon Lamunière, comisario especializado en arte y nuevos medios, era el encargado del comisariado de la página web de la Documenta X, que albergó una pionera exhibición de net art. Tras proclamarse la clausura de la web una vez finalizado el evento y decretarse su posterior trasvase a un soporte material CD-ROM para su comercialización, el teórico y hacktivista esloveno Vuk Cosic copió en otro servidor la información del original. La polémica, desde entonces, queda servida como algo intrínseco a las siempre tensas relaciones entre el arte, los dominios virtuales y las instituciones.

En cuanto a la llegada del arte tecnológico a España, cabría comenzar aludiendo al proyecto ArtFutura de Montxo Algora, que en 1990 pone en marcha hasta día de hoy un festival de Cultura y Creatividad Digital explorando las innovaciones más representativas de los nuevos medios, la realidad virtual, el diseño 
de interacción y la animación digital ${ }^{2}$. Asimismo, el artista multimedia Antoni Muntadas, partiendo de la experimentación con las tecnologías computacionales, elabora un artefacto de cyber-artivismo denominado The File Room ${ }^{3}$ : prototipo abierto de sistema operativo que invitaba a reflexionar sobre las nociones de archivo, almacenamiento y censura cultural en los aún rudimentarios parajes digitales ${ }^{4}$. Claudia Giannetti, además, creó en el año 1993 la Associació de Cultura Contemporània L'Angelot, en Barcelona, considerada como el primer espacio en el estado español especializado en arte electrónico ${ }^{5}$. A través de la editorial del centro se publicaron numerosos libros, entre ellos el ya clásico Arte en la Era Electrónica. Perspectivas de una nueva estética (1997), de cuyo evento homónimo "Primer Congreso Internacional Arte en la era electrónica: perspectivas de una nueva estética" (Centre de Cultura Contemporània de Barcelona, 1997) fue directora Giannetti. Ese mismo año también vería la luz el portal web Aleph, que podemos enmarcar dentro del acontecimiento de carácter internacional y transitorio que supuso el auge de las prácticas artísticas en la red $^{6}$. Deberíamos destacar el interés inmediato que suscitan en Brea los nuevos medios y que comenzaría a manifestarse más concretamente desde la exposición Anys 90. Distància zero (Centre d'Art Santa Mònica, 1994) ${ }^{7}$. En esta exposición, donde lo audivisual conduce hacia la desmaterialización de la obra concediendo mayor importancia al proceso creativo en sí mismo, alcanzamos a entrever los indicios que nos orientan hacia los futuros postulados teóricos sobre la cultura RAM ${ }^{8}$.

Quizá por ser, en parte, una recopilación de textos escritos en diferentes periodos o, quizá, por una tendencia a teorizar más allá del presente, la obra de Brea cultura_RAM. Mutaciones de la cultura en la era de su distribución electrónica (2007) ofrece un complejo entramado de tesis donde se entrecruzan el análisis de la contemporaneidad referente al autor, las posibilidades de agencia frente al devenir digital del mundo, y algunas "futurotopías"9 de extrema lucidez. La fascinación por el auge de las nuevas tecnologías no indujo a nuestro autor a la ceguera. Tal vez, lo más interesante desde el presente es la posibilidad de relectura que permiten los textos de Brea, estableciendo una analogía con lo que él mismo intuía para el porvenir ${ }^{10}$. Tras una lectura atenta, el mensaje que porta su teoría comunica sin apenas interferencia alguna con el contexto en que vivimos, sobre todo cuando consideraba necesario, frente a la digitalización de los procesos de producción, "proponer los conceptos e instrumentos que hagan posible, a la postre y todavía, la crítica de su economía politica"11.

\footnotetext{
2 http://www.artfutura.org/v3/.

${ }^{3}$ Es posible acceder a la pieza recuperada en el archivo online de la plataforma web rizhome, último acceso 26 de febrero de 2021, https://sites.rhizome.org/anthology/thefileroom.html.

${ }^{4}$ Para una más detallada contextualización de este proyecto véanse las consideraciones expuestas por el entonces director del centro Arteleku, en cuya sede se presentó el proyecto en 1994, Santiago Eraso, "Luchas por la libertad política y creativa en Internet", último acceso 26 de febrero de 2021, https://santieraso.com/2013/01/06/luchas-por-la-libertad-politica-y-creativa-en-internet/.

5 Acerca de la puesta en marcha del centro barcelonés consultar Claudia Giannetti, L'Angelot: Work in progress $1993-1997$ (Barcelona: ACC L’Angelot, 1997).

${ }^{6}$ Para una lectura crítica del nacimiento, consolidación y deriva de Aleph dentro del contexto del arte español véase: Jesús Carrillo, “Aleph, la web como espacio de acción paralela”, Desacuerdos. Sobre arte, politica y esfera pública en el Estado español, 2 (2005): $123-143$.

7 Tras la muerte de Brea aparece esta publicación que nos brinda una esclarecedora aproximación de rigor histórico a su trayectoria profesional: Juan Albarrán, "José Luis Brea y la historia última del arte en España”, texto redactado para la web del proyecto Brumaria (www.brumaria.net) y reproducido en Salonkritik, 12 de noviembre de 2010.

${ }^{8}$ Acerca del término cultura_RAM, acuñado por Brea, y su relación con las mutaciones digitales, el archivo y la recuperación de la memoria-documento, véase: Fernando Broncano, "A propósito de José Luis Brea: del archivo a la RAM", Caracteres. Estudios culturales y críticos de la esfera digital, 3, n 1 (2014): 273-289.

9 "Microescenarios abstractos hipotéticamente situados en algún punto no fijable del futuro. Son escrituras rescatadas de una mirada fortuita en un tiempo por venir, al que acceden en un imaginario dejà vú invertido. Seguramente, con la intención de insinuarnos una ontología crítica del hoy, desde su reverso incumplido... El conjunto de estas futurotopías (aquí recogida y revisada [sic.]) se publicó originalmente como serie de entregas en el suplemento cultura|s de La Vanguardia", en José Luis Brea, cultura_RAM. Mutaciones de la cultura en la era de su distribución electrónica (Barcelona: Gedisa, 2007): 93.

${ }_{10}$ Véase Miguel Vega Manrique, "José Luis Brea. Teoría-crítica en la era del mundo-Internet", Los flujos de la imagen. ASRI, 17 (septiembre, 2019): 38-51, para un análisis más pormenorizado de los planteamientos teóricos del autor a través del análisis de dos conceptos fundamentales de su obra: cultura RAM y capitalismo cultural electrónico.

11 Brea, cultura_RAM, 53.
} 
Con la iniciativa puesta en marcha por Luis Fernández y Ricardo Echevarría, será Brea el rostro visible que alzará la voz a través de Aleph y los embrionarios dominios cibernéticos, liderando un soporte digital que albergaba obras de net art y e-shows, al mismo tiempo que una surtida sección de net critique dirigida a engrosar el debate teórico-crítico con publicaciones y traducciones de textos. Siguiendo a Juan Martín Prada, especialista en la materia y continuador/discípulo de Brea por lo que al arte y la cultura digital se refiere, tomaremos el uso y la grafía net art en alusión "a todas aquellas obras para las que las tecnologías basadas en redes de telecomunicación (no solo Internet) son condición suficiente y necesaria para su existencia, siendo imprescindible acceder a alguna de esas redes para poder experimentarlas"12.

El escenario del arte contemporáneo se plantea como un panorama heterogéneo de apertura e inagotables posibilidades ante la irrupción de los nuevos medios y el avance de la tecnificación, que ineludiblemente condicionarán el desarrollo de las prácticas artísticas. La fascinación por los mismos parece dictar a finales de los noventa la medida del devenir futuro de la globalización y de las formas de interacción social, lo cual vendría requerido de paradigmas teóricos afines a la figura del artista contemporáneo y de la renovada noción de obra de arte en la era digital. Si nos sumergimos en los textos de cultura_RAM..., vemos que Brea reserva un apartado íntegramente dedicado a las prácticas artísticas en la era del capitalismo cultural electrónico. Entre las tareas que encomienda a dichas prácticas, hallamos la crítica de las políticas de la representación, junto al desarrollo e interposición de dispositivos de criticidad que evidencien las dinámicas de configuración de imaginarios hegemónicos para posibilitar su desmantelamiento. Al mismo tiempo, estas prácticas deberán implementar "políticas del acontecimiento" con el fin de producir experiencia y comunidad, y "presionar a favor de la implantación desregulada de las nuevas economías de distribución, contra las establecidas de comercio [...] sin que la plena absorción indiferenciada en la industria del espectáculo fuera destino seguro"13.

Atendiendo a estas cuestiones teóricas, vemos que existe una estrecha correlación con la praxis curatorial que llevó a cabo el propio Brea. Para una mejor comprensión, señalaremos algunos de los participantes activos de Aleph, entre los cuales encontramos el colectivo La Société Anonyme (1990), que engloba a un conjunto de artistas y teóricos dedicados a la investigación y el desarrollo experimental de las relaciones entre las producciones artísticas y el pensamiento crítico $^{14}$. En la organización de Aleph, la colectividad es el principio constitutivo para la innovación y la creación, que tienen como objetivo producir cambios sustanciales en los modos de vida a medio plazo. La transparencia y el anonimato que facilita Internet permiten desarrollar estas formas emergentes de comunidad como manifiestos no coartados que expresen la diversidad de subjetividades supraindividuales. En esta línea, y no solamente limitados al marco digital de Aleph, encontramos también la ferviente actividad del Critical Art Ensemble que, desde la fotografía, el diseño web, la performance y la actividad editorial, busca un impacto mediático enfocado en la consolidación de una resistencia electrónica mediante la "desobediencia cívica pacífica" y la "acción directa"15. Antoni Abad, Carmen Cantón, Ricardo Iglesias... son algunos de los artistas que también engrosaron la plataforma web con sus obras de net art. En todas ellas, "la digitalización supone la redefinición de las relaciones entre sujeto, representación y realidad"16.

En otros trabajos de net art como Heartbeat o The Tunnel People-ambos integrantes del acervo de Aleph y accesibles hoy en la web personal de la artista ${ }^{17}$, Dora García señala una ruptura entre el espacio

12 Juan Martín Prada, Prácticas artísticas e Internet en la época de las redes sociales (Madrid: Akal, 2015$): 14$.

13 Brea, cultura_RAM, 87.

14 El término La Société Anonyme es una cita duchampiana formulada por Katherine Dreier, Marcel Duchamp y ManRay. El grupo anónimo presente en Aleph era en gran medida una prolongación del mismo Brea, junto a otros aliados como Armando Montesinos, José Maldonado o Ricardo Echevarría, que disfrazaba su autoría tras esta agencia de nuevo cuño.

15 Brea desarrolla contemporáneamente estos conceptos en una conferencia titulada El teatro de la resistencia electrónica, que pronuncia en los Talleres de Arte de Montesquiú, el 11 de julio de 1999, y está disponible en el Tomo II de Aleph, que pertenece al archivo de José Luis Brea consultado en la biblioteca del MNCARS (páginas sin numerar).

16 Jesús Carrillo, Arte en la red (Madrid: Cátedra, 2004): 61.

$17 \mathrm{http}: / / w w w . d o r a g a r c i a . n e t /$ 
social y la escena de diálogo cotidiana, a la vez que propone un ejercicio de resistencia cercano al activismo. La obra de net art se encamina hacia la net critique cuando cuestiona el control y la desposesión de la experiencia, las sinergias sedantes de la sociedad del conocimiento ${ }^{18}$. Las condiciones de privacidad en Internet plantean una situación conversacional inédita a la hora de producir esfera pública y de proyectar las subjetividades en construcción: "Tales construcciones subjetivas e identitarias son resultado de un proceso imaginativo y performativo tanto cuando hablamos de individuos de 'carne y hueso' como cuando tratamos de personalidades 'virtuales' desarrolladas en la red"19. La red es ahora un espejo invertido donde convergen los mundos y las industrias de la comunicación y del espectáculo. Tras la rápida absorción de las innovaciones tecnológicas en la esfera de las prácticas artísticas "los conceptos de comunicación y comunidad irán siempre de la mano, así como los de distribución y accesibilidad"20.

La propuesta crítica y curatorial de Brea en la red toma impulso con la celebración del primer ARCO (1997) - pese a no haber formado parte del comité organizador- que albergó una sección dedicada al arte y los nuevos medios, el mismo año en que Aleph ve la luz ${ }^{21}$. Con estas palabras de entusiasmo: "Arco 97 representa el mundo que viene" 22 , la directora y ya reputada gestora de arte contemporáneo, Rosina GómezBaeza, abría las puertas de la feria de arte más icónica del país al futuro tecnológico adquiriendo un papel de vanguardia con un pie en Europa y otro en Latinoamérica. "En las propuestas de arte electrónico figuran conciertos de arte sonoro y manifestaciones de arte creado por ordenador y videoarte. También se presentará un CD-Rom multimedia de arte cibernético"23. El arte electrónico y el mercado fueron los protagonistas de ARCO 1997, presentes también en los IX Encuentros en el arte contemporáneo (1997) co-dirigidos por José Jiménez y Fernando Castro. Las cuatro secciones en que se dividieron los encuentros fueron: "Horizontes del arte latinoamericano", "Coleccionismo corporativo, institucional y privado", "Una aproximación al arte electrónico" y "Función del museo de arte del siglo XXI". En otras publicaciones también se destacaba cómo "De entre los tres apartados -arte sonoro, videoarte y arte cibernético- en que se sustenta la nueva sección, el último grito es el arte en la red" ${ }^{24}$, evidenciando la presencia central y novedosa de Internet con respecto al mercado del arte.

Si la incursión de las prácticas artísticas en la red fue casi instantánea, la indefinición y laxitud del fenómeno pronto se haría evidente: "la característica más problemática del net art será su enorme volatilidad, vinculada a la extrema obsolescencia de las tecnologías de la red" ${ }^{25}$. La emergente cultura digital, sorteando diversos altibajos desde su aparición, reclama progresivamente su lugar en las exposiciones de arte contemporáneo. También cabe destacar que la pronta aparición de Aleph y de eventos afines al deslumbramiento tecnológico, como la feria de Arco 97, no pasaron desapercibidas para la crítica:

La feria Arco 97 acoge por vez primera en su programa oficial la sección Arte Electrónico, como respuesta a la rápida evolución que están experimentando los nuevos medios [...] Es el territorio del arte cibernético o ciberarte,

18 Véase ::Online Communities.:, texto disponible en el Tomo II de Aleph, que pertenece al archivo de José Luis Brea consultado en la biblioteca de MNCARS (páginas sin numerar).

19 Carrillo, Arte en la red, 125.

20 Martín Prada, Prácticas artísticas e Internet, 16.

${ }^{21}$ Contrariamente a lo que algunas fuentes bibliográficas plantean, la primera feria de ARCO dedicada al arte electrónico es Arco 97. Bien es cierto que las dos siguientes ediciones, ARCO Electrónico1998 y 1999, contienen el adjetivo que más ilustra su condición tecnológica; aun así, la exhibición de 1997 a cargo del joven comisario y artífice técnico de Aleph Ricardo Echevarría, junto a los IX Encuentros en el arte contemporáneo co-dirigidos por José Jiménez y Fernando Castro, dejan plena constancia de la incursión de ARCO en el mundo electrónico.

22 "Arco 97 quiere difundir el arte latinoamericano en Europa", El País, 17 de enero de 1997, https://elpais.com/ diario/1997/01/17/cultura/853455605_850215.html

23 Ibidem.

${ }^{24}$ José F. Beaumont, “Arco se aproxima a los enigmas del arte electrónico", El País, 15 de febrero de 1997, https://bit. ly/3ewEWf2.

${ }^{25}$ Martín Prada, Prácticas artísticas e Internet, 17. 
la reserva donde campan por sus fueros los netartistas del ciberespacio (entendido como el universo virtual que existe al otro lado de la pantalla del ordenador) [...] Internet se perfila como un elemento creativo en el ciclo de la nueva estética. Aunque no todos lo tienen claro $^{26}$.

Brea adquiere mayor presencia durante las dos ediciones de ARCO Electrónico que se organizaron seguidamente, coordinando los seminarios Lo mejor de los dos mundos (1998), cuyo protagonista fue Aleph, y La era posmedia (1999), por encargo explícito de Rosina Gómez-Baeza ${ }^{27}$. Este papel de vanguardia electrónica que adopta la feria de arte con el temprano interés proyectado hacia los nuevos medios por parte del tándem Brea-Baeza sembrará el germen de posteriores vínculos en torno a las prácticas artísticas y curatoriales en la era del mundo-Internet. Las concepciones relativamente afines entre ambos acerca del arte, las instituciones y la financiación terminarían posibilitando el entendimiento y la colaboración mutuos. Tal como pone de manifiesto el volumen Servicio Público. Conversaciones sobre financiación pública y arte contemporáneo (1998), editado por Jorge Ribalta, Brea pensaba acerca de la institucionalidad del arte que el objetivo prioritario era intensificar y cualificar la experiencia de los receptores:

me parece que el objetivo básico de una política artística tendría que ser [...] aumentar la propia capacidad creadora de una población [...] No tanto el tratarla como audiencia, sino el convertirla lo más posible en protagonista activa de los procesos de comunicación creadora ${ }^{28}$.

Por lo que a Gómez-Baeza respecta, "el objetivo era claro: desarrollar teoría, creación artística y nuevos medios. No podíamos estar seguros del éxito. Constatamos y asumimos el rechazo. Él [Brea] publicó y yo inauguré" 29 . Y así, esa síntesis emprendedora de comprensión y afinidad cuyo origen se sitúa a finales de los noventa - con el desarrollo en ARCO de las propuestas que aunaron teoría y praxis en torno al arte y los nuevos medios-, resultaría el germen de lo que una década más tarde, en 2007, comenzaría su andadura en Gijón como un proyecto institucional dedicado íntegramente al arte y la cultura digital en el contexto español: LABoral. Centro de Arte y Creación Industrial. Gómez-Baeza, por entonces directora de la feria ARCO, destaca en la entrevista inédita concedida para el presente trabajo cómo "hasta 2007 trabajaba en la preparación del proyecto para Gijón a la vez que en ARCO. La actividad de esos años fue muy intensa, pero sobre todo había mucho interés por primar la viabilidad social, económica... que era muy complicado para una propuesta de esas características" ${ }^{30}$.

Brea, por su parte, teorizó sobre el modelo económico que correspondería a las nuevas prácticas artísticas en la era del capitalismo cultural electrónico. Salta a la vista cuán cercanos están sus planteamientos del gran proyecto que la asturiana plantea para su tierra natal:

El territorio de encuentro entre prácticas artísticas y tecnologías electrónicas abona el progresivo asentamiento de una "economía de distribución" [...] parece que el sentido de futuro de toda la economía cultural y del conocimiento avanza en esa dirección por lo que [...] la inversión en este espacio transversal supone sin duda una decisión estratégica a favor de un sector con enormes posibilidades de crecimiento e innovación ${ }^{31}$.

Desde el Principado de Asturias, la inversión en cultura tecnológica del proyecto se toma como una estrategia mercantil con miras al futuro. Además de estar cofinanciada por el Programa Europa Creativa de

\footnotetext{
26 Beaumont, "Arco".

27 Para más información acerca de los seminarios organizados por Brea para ARCO Electrónico y el contenido tratado en los mismos véase Carrillo, “Aleph".

${ }^{28}$ Jorge Ribalta, ed., Servicio público. Conversaciones sobre financiación pública y arte contemporáneo (Salamanca: Universidad de Salamanca y Unión de Asociaciones de Artistas Visuales, 1998), 168.

29 Rosina Gómez-Baeza, entrevista por Miguel Vega Manrique, 21 de mayo de 2018.

30 Gómez-Baeza, entrevista.

31 Brea, cultura_RAM, 175.
} 
la Unión Europea, la entidad nace agregada al Campus de Excelencia Internacional de la Universidad de Oviedo, lo cual debiera facilitar la permeabilización de su presencia en múltiples ámbitos de la sociedad asturiana. No debemos pasar por alto la idea de integración que subyace a todos los emplazamientos de la Milla del Conocimiento (distrito Este de Gijón), de la cual pasará a formar parte LABoral, junto a seis facultades del campus universitario, dos centros tecnológicos, el Conservatorio Profesional de Música y Danza de Gijón, el Jardín Botánico Atlántico y el Hospital de Cabueñes.

Hacia el año 2007 LABoral es uno de los mayores espacios expositivos (14.000 metros cuadrados incluyendo el total del complejo) en España, cuyo emplazamiento paisajísticamente privilegiado lo convierte en un oasis del sueño tecnológico. En su vinculación directa entre arte, nuevas tecnologías, creación industrial e innovación empresarial está el núcleo aglutinador donde confluye la propuesta inicial de Gómez-Baeza para su puesta en marcha, que contará con la colaboración del filósofo asturiano Juan Cueto como ideólogo. Conviene tener presente, una vez hemos llegado aquí, la puntualización que aporta Jesús Carrillo acerca del centro asturiano: "Es interesante notar cómo esa noción inclusiva, multidisciplinar y productiva de 'cultura visual' aparece sistemáticamente vinculada a la de 'nuevas tecnologías', presentándose como los pilares centrales de la definición programática del nuevo museo o centro"32.

Antes de proseguir, no debemos pasar por alto otros procesos de institucionalización paralelos, como el de Medialab Madrid que abrió sus puertas en Conde Duque el año 2002 aunando investigación, producción y difusión cultural en diversas áreas mediante el aprovechamiento de la tecnología digital de forma pionera. Aunque supone el antecedente más directo para LABoral, las dimensiones y la ambición de este último proyecto van más allá de la propuesta del centro madrileño, como intentaremos poner de manifiesto en el siguiente apartado. Otros de los más claros antecedentes es, a partir de 2006, el centro de creación artística Matadero, ubicado en Madrid. El rol central que se da a las tecnologías y al nuevo paradigma de la interactividad en los discursos iniciales de estas fábricas de la cultura será la piedra angular para la institucionalización de los nuevos medios. No obstante, LABoral es un caso paradigmático por su localización geográfica de espaldas a la ciudad, siguiendo el imperativo de la arquitectura primigenia de Luis Moya durante el franquismo, en 1948, frente a los otros proyectos ${ }^{33}$. Desde la brevedad del formato, trataremos en lo que sigue de dilucidar la deriva del centro gijonés que abre sus puertas a finales de marzo del 2007, con la antigua directora de ARCO a la cabeza, hasta que en 2011 cede el barco varado en su ciudad natal a manos de Benjamin Weil.

\section{Del fin del net art a la redefinición de las prácticas artísticas en el nuevo milenio}

Peter Weibel, teórico, artista y comisario austríaco especializado en arte y nuevos medios, organizó las exposiciones art and global media (1998-1999) y net_condition (1999) en diferentes ciudades: Barcelona, Graz, Karlsruhe... junto a seminarios destinados a pensar sobre el asunto en cuestión. Partiendo de su experiencia en la materia, Weibel creía que "una exposición centrada en el impacto social, económico y político de los nuevos medios solo puede tener lugar dentro de estos mismos medios" ${ }^{34}$. El producto final en forma de volumen recopilatorio de textos: net_condition: art and global media (2001) coincide con la aparición

\footnotetext{
32 Jesús Carrillo, "Las nuevas fábricas de la cultura: los lugares de la creación y la producción cultural en la España contemporánea”, en Propiedad intelectual, nuevas tecnologías y acceso a la cultura, coords. Alberto López y Eduardo Ramírez (México: Centro Cultural de España en México, 2008), 287.

33 Acerca de la institucionalización del arte en España y el desorbitado auge de centros de creación y exposición véase: Alberto López Cuenca y Noemí de Haro García, “Arte contemporáneo, infraestructura y territorio en el Estado de las autonomías”, en Por el Centro Guerrero (2009-2011). Política cultural, crisis institucional y compromiso ciudadano, coord. Gabriel Cabello (Granada: TRN-Laboratorio artístico transfronterizo, 2014), 11-20.

${ }^{34}$ Peter Weibel y Timothy Druckrey, eds., net_condition: art and global media (Karlsruhe: Engelhardt y Bauer, 2001), 8, traducción propia.
} 
de la web 2.0 y el canto de cisne del net art, ofreciéndonos una amplia recopilación de visiones acerca del fenómeno de los medios electrónicos, desde la televisión a las prácticas artísticas, todo ello sin obviar la celebrada World Wide Web $^{35}$.

En pleno apogeo del net art, Claudia Giannetti había comisariado conjuntamente con Peter Weibel, Jeffrew Shaw y Toshiharu Ito la emblemática exposición net_condition, que ya mencionamos con anterioridad. De forma individual, la investigadora y teórica italo-brasileña monta a escasos tres años una de las primeras muestras dedicadas al arte interactivo: online y offline Link_Age (Gijón, Madrid, México y São Paulo, 2001). Poco después, en el contexto español del arte contemporáneo, es cuando Brea aporta como comisario su concepción del arte electrónico en la exposición La conquista de la ubicuidad (Espacio XTRA-Fundación Caja Murcia y Centro Atlántico de Arte Moderno, 2003 - Koldo Mitxelena Kulturunea Fonoteka, 2004). En sus propias palabras:

Aunque el objetivo aparente de la conquista de la ubicuidad es realizar una breve historia del net.art, no nos planteamos hacerlo desde la perspectiva inmanente de un género o una forma artística más o menos reciente y consolidada, sino [...] desde la [...] emergencia en el contexto de la transformación de las prácticas de significación, representación y comunicación que está teniendo lugar en las sociedades contemporáneas ${ }^{36}$.

El concepto de ubicuidad que cierra el título de la muestra responde a la resistencia que, según Brea, las nuevas prácticas artísticas imponen frente a las economías de mercado. La transición de la economía de comercio a la economía de distribución es parte intrínseca a la crítica sobre el capitalismo cultural electrónico de Brea. Vemos ahora cómo en su dialéctica, a comienzos de los dos mil, ya estaba en pie cierto distanciamiento con respecto a la forma mercancía, no del todo ajeno al influjo del pensamiento milenarista benjaminiano, que en cierta medida era consustancial a la obra de net art y tal vez a ello se debiera su escasa repercusión en el mercado $^{37}$. Como podemos constatar, los postulados teóricos del autor también se trasladan y materializan en la práctica curatorial que lleva a cabo de forma casi marginal y periférica dentro del mundo del arte.

En el estadio de umbral que circunda la síntesis referida de teoría y praxis, "el nuevo régimen [...] todavía está por llegar y asentarse" $38 \mathrm{y}$, con total convencimiento, Brea plantea que dicho "advenimiento: si llega a cumplirse (cosa que no dudamos: o por la que, dicho de otra forma, apostamos decididamente) obligará a una lectura retrospectiva del net.art" ${ }^{\prime 39}$. En la misma publicación, donde colaboran destacados nombres del debate a nivel internacional, como Hal Foster, Benjamin Weil (sucesor en 2011 de Gómez-Baeza en la dirección de LABoral) o Alexander R. Galloway, el comisario especializado en arte y nuevos medios (y asiduo colaborador, asimismo, de LABoral), Steve Dietz, reproduce casi literalmente las palabras de Brea cuando dice que "el resultado es sólo cuestión de tiempo; no se trata de si el net.art acabará formando parte de las estrategias de exhibición o de la economía de comercio, sino de cuándo lo hará”40, antes de elaborar una defensa acérrima del mismo parafraseando a Linda Nochlin en ¿Por qué no ha habido grandes artistas de la Red?

Estas devotas manifestaciones que rozan lo excéntrico hacia el net art pueden servirnos para tomar el pulso de la muestra y del impotente final auspiciado por el avance del software 2.0, que relegó a un periodo muy concreto de tiempo las prácticas que venimos señalando. Obras de net art de diferentes artistas (Mark

\footnotetext{
35 Autores como Manuel Castells, Jürgen Habermas, Pierre Bourdieu o Claudia Giannetti reflexionan en el citado volumen sobre los conceptos más acuciantes del momento: condición social, comunitaria, medial, ideológica, crítica y artística en la era del capitalismo cultural electrónico, tal como Brea lo definiría poco después.

36 José Luis Brea, coord., La conquista de la ubicuidad (Murcia: A. G. Novograf [cat. exp.], 2003), 10.

${ }_{37}$ Vuelvo a referir al trabajo antes citado en la nota 10, Vega Manrique, "José Luis Brea", 44-49, donde problematizo las tensiones que derivan de un posible alejamiento de la forma-mercancía inducido por la fascinación precoz ante las mutaciones a partir de la digitalización de los procesos de producción.

${ }^{38}$ Brea, La conquista, 11.

39 Brea, La conquista, 11.

${ }^{40}$ Brea, La conquista, 13.
} 
Amerika, Lev Manovich, Dora García, Ben Benjamin, Antoni Muntadas, Vuk Cosic o el colectivo Critical Art Ensemble) engrosaron el acervo expositivo, mostrando al público algunos de los trabajos más significativos del arte en la red. Para entender la necesidad de una búsqueda renovada por lo que a las prácticas artísticas compete ante el continuo refinamiento de las telecomunicaciones, sirva el alegato que Brea enuncia al porvenir desde el catálogo de la muestra:

El net.art no pertenece a nuestro tiempo. De la misma forma que habitan nuestra época múltiples formas pertenecientes al pasado, el net.art ha atravesado (fugazmente) nuestros días tan sólo como humilde heraldo de un tiempo por venir. Todo lo que él tenía que decir se refiere a un tiempo que vendrá, a la forma que adoptará la cultura en ese tiempo futuro ${ }^{41}$.

Parece evidente, llegados a este punto, la cercanía entre las exposiciones comisariadas por Weibel, mencionadas al inicio del presente apartado, y Brea. Salvando el característico tono de radicalidad profética de este último, ambos sitúan el foco de sus propuestas en el mismo punto: la historicidad del net art con respecto a la aparición de un nuevo software que vendría para renovar las comunicaciones a través de la virtualidad plena.

Rosina Gómez-Baeza señala, desde su óptica personal:

La producción de Brea hacia los años dos mil tiene presente los cambios que se producen en el mundo a partir de la incorporación del universo digital. Él fue el portavoz, el profeta de la nueva realidad, como también lo fuera su contemporáneo Peter Weibel ${ }^{42}$.

Cuando se plantea por esas mismas fechas (2001-2002) reflotar el conjunto arquitectónico de la antigua Universidad Laboral de Gijón, la por entonces directora de ARCO se postula para encabezar un proyecto en relación al arte contemporáneo y la innovación industrial. Es por entonces cuando decide presentar una sólida propuesta de centro transversal al arte, la ciencia, la tecnología, la industria y la sociedad. La obsolescencia del net art va dejando paso a una manera más amplia de concebir el desarrollo de las prácticas artísticas en el nuevo milenio. Al plantear una iniciativa como LABoral, las innovaciones tecnológicas y la expansión de la red a casi todos los ámbitos de la vida confluyen con una concepción cada vez más transversal e integradora entre el arte, el progreso y la sociedad. Para una primera aproximación en líneas generales al proyecto preferimos acudir a la forma en que la antigua directora nos transmite su propuesta:

LABoral supone abrir la puerta al mundo y abandonar la idea de que el arte de hoy tiene que rendir pleitesía a los valores del pasado. Hay que abrirse al futuro. Es lo que quise proponer a mi querida tierra. Pongámonos a prueba en aceptar el hoy: herramientas digitales, rol del artista, hacer pensar a las comunidades... ${ }^{43}$.

El plan de producción artística y curatorial para LABoral se vincula en todo momento con el crecimiento económico y el desarrollo industrial, con la intención de "lograr una auténtica fusión entre creatividad e industria y para ello se plantea promover un diálogo entre creadores y empresas, en una alianza cuyo fin último es abrir las puertas a la innovación" ${ }^{4}$. En cierta medida, lo que LABoral intenta es:

\footnotetext{
${ }^{41}$ Brea, La conquista, 68.

42 Gómez-Baeza, entrevista.

43 Gómez-Baeza, entrevista.

${ }^{44}$ Ana Botella, coord., Laboral, un espacio para el intelecto entre arte, ciencia, tecnología e industrias creativas (Gijón: LABoral. Centro de Arte y Creación Industrial, 2007), 5.
} 
[dar] respuesta a la necesidad de contar en España con un espacio dedicado a la experimentación artística y [...] el desarrollo de la emergente actividad de aquellos creadores que desarrollan sus conceptos expresivos conectando las posibilidades que ofrecen las actuales Tecnologías de la Información y de la Comunicación con los nuevos soportes para las artes visuales, el diseño, la moda o los videojuegos ${ }^{45}$.

La atención al medio ocupa el centro del proyecto junto al eje tecnológico, la innovación y la mutación del paradigma productivo. En el Plan Director del año 2004, donde Gómez-Baeza detalla el estudio previo, objetivos, alcance, propuesta de programa, modelo de gestión, programa de trabajo, organización y equipo, el proyecto tenía por nombre Centro de Arte Actual y Creación Industrial de la Universidad Laboral de Gijón ${ }^{46}$. Los modelos tomados a nivel socio-económico eran los museos Guggenheim de Nueva York y Bilbao y la Tate Modern de Londres. En cuanto al concepto de centro abierto receptor de prácticas como el diseño, el Media Art o la Moda, establece paralelismos con el MoMA, el MNCARS, o el por entonces recién inaugurado Palais de Tokyo en París. Por lo que a la producción, investigación y educación se refiere, la directora en potencia decide fijarse en Arteleku, Walker Art Center o MIT Media Lab. Sin embargo, es el Centro de Arte y Medios Tecnológicos de Karlsruhe: ZKM, que aglutina en su haber diversos museos (Media Museum, Mediateca) e institutos de investigación (Visual Media, Net Development, Media and Economics...) la principal fuente de inspiración. Su contacto y amistad con el director, Peter Weibel, facilitó el intercambio al mismo tiempo que la concepción de un centro multidisciplinar a la vanguardia en las prácticas artísticas del nuevo milenio.

Por otra parte, los contenidos del proyecto deberían abarcar las artes visuales, el diseño gráfico e industrial, la arquitectura, la moda, el arte público y el Land-Art. Atendiendo a la centralidad de la producción en sí, se proponían también dispositivos innovadores como laboratorios de investigación y experimentación artística multidisciplinar (conexión entre tecnología y artesanía: Art-Labs), o la formación mediante ciclos, talleres, tertulias... El conjunto se revela como un "espacio interdisciplinar [...] para favorecer el intercambio artístico" 47 , al mismo tiempo que como "un centro para la investigación, formación y producción artística y técnica, así como para la proyección de las nuevas formas de arte y creación industrial"48.

Un ejemplo concreto de todo esto sería la Plataforma 0 , dedicada a la investigación, producción, educación y exposición de contenidos, con una estructura modular y flexible integrada por programas y servicios para el trabajo en grupo, colectivos, artistas individuales y personal educativo ${ }^{49}$. Dentro de ella se integran el LABoratorio Sonido ${ }^{50}$ (cuyo programa se detuvo hace un año tras escasos cuatro años de funcionamiento) y fabLAB Asturias ${ }^{51}$, a su vez conectado con la red mundial de Fablabs ${ }^{52}$ (cien laboratorios de treinta países). Una de las secciones más innovadoras del centro LABoral, Mediateca_Archivo ${ }^{53}$, condensaba las funciones de repositorio digital para la interacción recíproca de contenidos en red de acceso gratuito, siendo actualizada día a día con la producción del Centro de Arte. Sin embargo, algo no funcionó como debiera ya que Mediateca_Archivo se encuentra desde hace tiempo fuera de servicio por "problemas técnicos". El mismo caso de servidor caído podría aplicarse a la Wiki fabLAB Asturias y la Wiki LABoratorio de Sonido.

45 Botella, Laboral, 5.

46 El Plan Director del Centro de Arte Actual y Creación Industrial de la Universidad Laboral de Gijón (2004) es facilitado con generosidad para el presente trabajo por la propia Rosina Gómez-Baeza, al igual que el resto de documentos citados y pertenecientes al archivo personal de la misma. En dicho documento se recogen tres años de rigurosa investigación que avalan la proposición para el proyecto de centro.

47 Botella, Laboral, 5.

48 Botella, Laboral, 5.

49 www.laboralcentrodearte.org/es/plataformacero.

${ }^{50} \mathrm{http}$ //www.laboralcentrodearte.org/es/plataformacero/lsonido.

${ }^{51}$ www.laboralcentrodearte.org/es/plataformacero/fablab.

52 Talleres de fabricación digital dedicados a la producción de objetos materiales a través de máquinas controladas informáticamente. Convergen en su estructura la industria y la sociedad.

${ }^{53}$ www.laboralcentrodearte.org/es/r/m_a/mediateca_archivo/view. 
Coincidiendo con la inauguración del centro, el 30 de marzo del 2007, Brea pronuncia de cuerpo presente una conferencia titulada La era de la imagen electrónica ${ }^{54}$, que a su vez acompaña de un seminario dirigido por él mismo. El título alude a las temporalidades que llevan en su ADN el sello tecnológico del progreso y a las reflexiones sobre la autonomía de la imagen en la era de las sociedades del conocimiento. Entretanto, Brea también propone un despliegue histórico acerca de los modos técnicos que adopta la imagen para "darse" a lo largo de diferentes épocas, hallando en la visualidad del cristianismo y la construcción del relato de la verdad su punto de apoyo primigenio.

Varias de las cuestiones expuestas por Brea en la conferencia que pronuncia con motivo de la apertura del centro se reflejan en el programa del mismo: "La sociedad de la información contemporánea percibe y construye su realidad sobre todo a través de la imagen. LABoral propone una reflexión sobre la preeminencia de la imagen técnica independiente de sus orígenes" ${ }^{55}$. Esta alusión al dominio de la e-image entre el conjunto de la sociedad, al igual que otros ejes conceptuales y programáticos afines al centro asturiano, nos remiten al grueso del corpus teórico de Brea. Los procesamientos de información típicos de la cultura_RAM y de La era de la imagen electrónica se ponen en práctica en las salas de exposición (como veremos en el último apartado) y en la plataforma web de LABoral ${ }^{56}$.

En ese momento, el teórico español reflexionaba sobre estas cuestiones dando forma al libro que publicaría unos años después, Las tres eras de la imagen (2010), cuyo punto de llegada reside en el simbolismo irreal de la imagen-tiempo en perpetuo flujo de interconexiones ${ }^{57}$. Cual aparición, "las imágenes electrónicas carecen de toda realidad [...] apenas temporales e incapaces como tales de dar testimonio de duración" 58 , por lo que adquieren un "devenir pensamiento" en favor de la estancia localizada. Las teorías estéticas acerca de la visualidad y de la imagen inmaterial desplegadas por Brea abordaban un terreno fundamental para la contemporaneidad de hace aproximados diez años, manteniendo una interlocución directa con diferentes actores del debate nacional e internacional, sobre todo cuando de pensar el futuro se trataba ${ }^{59}$. A modo de síntesis sobre la teoría desplegada por Brea durante su intervención en el recién inaugurado centro asturiano, podríamos destacar que la era de la imagen electrónica produce un sujeto múltiple que conecta con las lógicas de las economías de la experiencia; a través de los nuevos modos de subjetivación aparecen inéditos factores de resistencia y emancipación abiertos a producir otros imaginarios posibles, otras formas de vida en común.

Con todo lo que antecede, hemos intentado poner de relieve, desde un primer momento, la presencia más o menos directa, pero en todo caso significativa de Brea en el centro de arte gijonés, así como la de sus tesis acerca del capitalismo cultural electrónico y la cultura RAM. Resulta difícil no concebir, llegados a este punto, algún tipo de vinculación entre la mezcla de teoría y praxis llevada a cabo por Brea, con carácter relativamente pionero para el contexto del arte y los nuevos medios en el estado español, y el centro asturiano. Pese a no formar parte del comité organizador ni tener implicación institucional alguna con el proyecto, Gómez-Baeza -personalmente- y lo expuesto hasta el momento resaltan la influencia de Brea en cuanto al sustento material-

\footnotetext{
${ }^{54}$ José Luis Brea, "La era de la imagen electrónica”, Contrastes. Revista internacional de filosofia, suplemento 13 (2008): 15-28.

${ }_{55}$ Memoria: cuatro años de laboral. 30 de marzo de 2007-31 de mayo de 2011 (Gijón: LABoral. Centro de Arte y Creación Industrial, 2011), 16.

56 www.laboralcentrodearte.org.

57 Podríamos plantear, como una posible continuación de este último trabajo de Brea, cercano a los estudios, visuales, la más reciente publicación de Juan Martín Prada, El ver y las imágenes en el tiempo de Internet (Madrid: Akal, 2018).

58 José Luis Brea, Las tres eras de la imagen. Imgen-materia, flim, e-image (Madrid: Akal, 2016), 67.

59 Vid. "Mutaciones", seminario realizado entre el 10 y el 11 de diciembre del año 2005 en el Centro de Arte Contemporáneo y Creación Industrial de Gijón, dentro del ciclo Cultura en Democracia. Balance y perspectiva, organizado por el Ministerio de Cultura. Los participantes: Javier Echeverría, José Luis Brea, Jorge Fernández León, Juan Cueto, Marina Núñez, Jorge Wagensberg y Carlos Alberdi, abordaron el futuro del centro asturiano desde las perspectivas de los diferentes perfiles encarnados individualmente, http://va.www.mcu.es/publicaciones/docs/ccd/ccd8.pdf.
} 
teórico de LABoral ${ }^{60}$. Antes de continuar, conviene tener presente que, si bien es cierto el irrelevante número de traducciones a otras lenguas del trabajo de Brea, lo expuesto en este epígrafe constata tanto el interés y conocimiento de las últimas tendencias en el debate internacional por parte del autor, como su estrecho lazo de interconexión y colaboración en múltiples trabajos, traducciones y publicaciones conjuntas. A este respecto, no parece disparatado asignarle un lugar de relevancia en la temprana asunción de los paradigmas prácticos y teóricos sobre arte y nuevos medios durante la época de cambio de siglo en el estado español ${ }^{61}$.

\section{LABoral. Centro de Arte y Creación Industrial (2007-2011) a través de cinco exposiciones clave}

FEEDBACK. Arte reactivo a instrucciones, a inputs o a su entorno (LABoral, 2007) у LABciberespacios (LABoral, 2007) son dos de las cuatro exposiciones que inauguraron conjuntamente el centro de arte asturiano. El primero de los proyectos curatoriales proponía un recorrido histórico a través de las obras de arte que de una u otra manera se activan mediante instrucciones o inputs, "ofreciendo así una narrativa común a la multiplicidad de historias existentes en eso que hoy llamamos 'arte de los nuevos medios" " ${ }_{62}$. Una vez superados los límites del net art y dada la plena integración de las prácticas artísticas en los nuevos medios, los cuatro núcleos expositivos en los que se dividía la muestra facilitaban al espectador un recorrido hacia la integración del arte en la telemática, el algoritmo, la luz y la imagen en movimiento: (1) desde las instrucciones: algoritmos/máquinas dibujantes, a sistemas abiertos: cibernética, (2) telemática y conexiones globales, (3) arte cinético/óptico y (4) a la TV y cinemática.

Combinando obras de artistas aparentemente dispares por lo que a periodos y corrientes artísticas se refiere, FEEDBACK. Arte reactivo a instrucciones, a inputs o a su entorno planteaba con su amplitud y complejidad una recapitulación histórica para contextualizar el nacimiento del nuevo centro asturiano de creación artística. Así, despojados de una canonización cronológica, interactuaban en la misma sala seis Retroreliefs (1965) de Marcel Duchamp con la obra fílmica Ein Lichtspielschwarzweissgrau (Juego de luces negro blanco gris) (1930) de László Moholy-Nagy, o una más contemporánea escultura cibernética Death Before Disko (2005-2006) de Herwig Weiser que se activaba "produciendo destellos como respuesta a la entrada en vivo de sonidos del espacio exterior vía Internet" ${ }^{63}$. A través de una inusual constelación de obras e instalaciones, el espectador accedía al universo de lo que podía preverse para el futuro vanguardista de LABoral (como) Centro de Arte y Creación Industrial.

Al mismo tiempo, LABciberespacios trataba de alejarse en todo lo posible del reduccionismo especialista reservado a cada disciplina (teatro, danza, artes plásticas, vídeo, diseño...), de la autonomía que aísla el arte de la ciencia. Serían Gerfried Stocker y Manuela Pfaffenberger los comisarios encargados de la muestra. Ambos afines a la plataforma digital ArsElectronica ${ }^{64}$ y a su sede en Austria, ejemplificaban la vinculación del centro asturiano con el exterior, a la vez que una vocación de estricta contemporaneidad. Los diez artistas y colectivos seleccionados por concurso para exhibir sus trabajos reflexionaban sobre las relaciones

\footnotetext{
60 "No estuvo implicado directamente en el proyecto, pero sí que influyó mucho en mí. Para mí era un referente: todavía tengo su mail ahí (señalando al ordenador sobre la mesa visiblemente emocionada), me da mucha pena borrarlo", Gómez-Baeza, entrevista.

${ }^{61}$ Véase cómo casi contemporáneamente sucedió algo similar con el campo de los estudios visuales, uno de sus últimos intereses académicos que asumió, a la ola del giro norteamericano iniciado desde el foro de la revista Artforum, como cambio de paradigma histórico desde la disciplina de la estética. Brea fue corresponsal para esta revista en España y también puso en marcha y dirigió la revista Estudios Visuales. Asimismo, fue el director del I Congreso Internacional de Estudios Visuales en Madrid, ARCO 2004, y del Encuentro Internacional de Estudios Visuales: Geopolíticas de la imagen en las sociedades del conocimiento, en ARCO 2006. Todo ello queda recogido en el volumen José Luis Brea, ed., Estudios visuales. La epistemología de la visualidad en la era de la globalización (Madrid: Akal, 2005).

${ }^{62}$ Christiane Paul y Jemima Rellie et al., FEEDBACK. Arte reactivo a instrucciones, a inputs o a su entorno (Gijón: LABoral Centro de Arte y Creación Industrial [cat. exp.], 2007), 26.

${ }^{63}$ Paul y Rellie et al., FEEDBACK, 188.

${ }^{64} \mathrm{https}: / / w w w . a e c . a t /$ news/.
} 
que tienen lugar entre lo físico y lo virtual ${ }^{65}$. Mediante una perspectiva interdisciplinar del conocimiento y de la práctica artística, esta exposición introducía las preocupaciones acerca de la innovación que irían unidas a la razón de ser del centro. La muestra estaba pensada como cierre de una etapa, la del net art, y la apertura a un tiempo futuro donde el espacio cibernético albergase formas nuevas de experimentación. E1 videoclip I'm a net artist (area3, 2003) "apunta a la presencia repartida del 'nuevo artista' por escritorios de casas y oficinas" "66. Rosina Gómez-Baeza reflexionaba en el catálogo de LABciberespacios acerca de la emergente figura del espectador proyectado a través del plasma e Internet: "Recuperamos para audiencias diversas la imaginería con la que se identifican los internautas, no el visitante casual de un centro de arte" ${ }^{\text {"67 }}$.

Para concluir con la inauguración de LABoral, haremos referencia a Gameworld (LABoral, 2007): una muestra que integraba el arte y el diseño de los videojuegos entre sus preocupaciones. Gameworld fue una ventana abierta al futuro y al mercado que no pasaba por alto las cifras desorbitantes de la industria a la que interpelaba. Faltaría no más que mencionar Extensiones-Anclajes (LABoral, 2007), la primera exposición dedicada a los artistas locales más contemporáneos en un acto de "glocalización", para completar el grueso proyecto curatorial que dejaba por inaugurado el centro ${ }^{68}$.

Dando un salto de dos años, nos vamos al 2009 para seguir con las exposiciones: El pasado en el presente y lo propio en lo ajeno (LABoral, 2009) y Feedforward. El ángel de la Historia (LABoral, 2009). En ambas, los conceptos de memoria, historia y fantasma/espectro hacen que recordemos el espíritu benjaminiano que impulsa y sobrevuela buena parte de las concepciones integradas y desarrolladas por Brea. Antes de proseguir, tal como el lector ha podido constatar, la construcción del relato que venimos elaborando sobre la praxis curatorial de LABoral (2007-2011) se articula gracias a las cuidadas y rigurosas publicaciones en forma de catálogo que acompañaron cada muestra. Los textos firmados por nombres de relevancia nacional e internacional en la materia, las traducciones de cada uno de ellos al inglés y otras traducciones de textos para ocasiones señaladas fueron una seña de identidad del centro.

Con la exposición El pasado en el presente y lo propio en lo ajeno el trabajo de archivo adquiere un papel central. Dos ensayos: "Por la otra puerta, es el llanto con su consuelo dentro", de Avery F. Gordon, y "De las contradicciones del espacio al espacio diferencial" de Henri Lefebvre, abren y cierran el catálogo respectivamente, delimitando así el marco teórico y discursivo de la muestra comisariada por José Luis Cienfuegos. Violencia, memoria, pasado oprimido, el unheimlich freudiano, fantasmas o espectros, terror de Estado y alternancia entre aparición/desaparición, presencia/ausencia, sobrevuelan el material expuesto. Un ejercicio a caballo entre el peculiar materialismo histórico de Walter Benjamin y los Espectros de Marx de Jacques Derrida conducía a "La temporalidad encadenada [...] decisiva en el planteamiento de la exposición [...] tras asistir metafóricamente a las numerosas apariciones espectrales que el lugar y su memoria convocan"69.

Aunque los trabajos de artistas como Martha Rosler o Hito Steyerl se ubicaron más allá del territorio español, al conjunto de la muestra subyacía el intento de encarar y reelaborar, desde la práctica artística, los fantasmas aún latentes en cada recodo del complejo arquitectónico franquista de la Universidad Laboral de Gijón. Obras como las de Juan José Pulgar (Ensambles) o Benjamín Menéndez (La cámara oscura,

\footnotetext{
${ }^{65}$ Procedentes de España, Finlandia, Austria o EE. UU., algunos de ellos fueron Hans Bernhard, area3, Hackitectura.net o el Colectivo RAN (Carlos Navarro, Ramón Prada y Javier Ideami).

${ }^{66}$ Christiane Paul et al., LABciberespacios (Gijón: LABoral Centro de Arte y Creación Industrial [cat. exp.], 2007$), 19$.

67 Paul et al., LABciberespacios, 11.

${ }^{68}$ Rosina Gómez-Baeza aclaraba así la incursión del término y su apropiación para LABoral Centro de Arte y Creación Industrial ubicado en Gijón: "Creemos que lo global y lo local no son fuerzas opuestas ni enemigas, sino hermanadas, relacionadas y dependientes una de la otra, como bien dice el sociólogo Robert Robertson, autor de Globalización (1992), a quien se debe el término 'glocalización', con el que quiso referirse a la peculiar relación y correspondencia entre global y local” (Botella, Laboral, 143). Sin embargo, durante sus inicios, hubo una fuerte reacción local hacia el centro LABoral por absorber gran parte de los recursos del Principado de Asturias para las artes, dejando poco espacio a proyectos de menor envergadura.

${ }^{69}$ Juan Antonio Álvarez et al., El pasado en el presente y lo propio en lo ajeno (Gijón: LABoral Centro de Arte y Creación Industrial [cat. exp.], 2009), 149.
} 
1994-2009; Paisaje Industrial, 1994-2001; Térmica y Gasómetro, 2001-2009) sí explicitaban claramente las alusiones al contexto local. Por medio de saltos espacio-temporales, fragmentos, superposiciones, se trataba de producir una reapropiación de la historia en el plano de la representación visual. Las fotografías o fotomontajes, junto a las videoinstalaciones que copaban prácticamente la totalidad del espacio expositivo, iban encaminadas a generar una especie de "fantasma comunitario", de "mediación de la esfera pública", en palabras de Brea, lejos del oscurantismo del pasado, con un claro predominio de la imagen-movimiento.

"El arte está atravesado por las nuevas tecnologías en todos los terrenos"70. Así nos introducía GómezBaeza a otra de las exposiciones más relevantes, a nuestro parecer, que albergó LABoral. Arte y tecnología, futuro y progreso, van de la mano en Feedforward. El ángel de la Historia. Walter Benjamin era erigido nuevamente faro desde el que iluminar el sentido de las prácticas artísticas como mediación de la esfera global interconectada, en consonancia con los cambios socio-políticos que tenían lugar por esas fechas ${ }^{71}$. Contemporánea a la crisis económica, Feedforward conectaba progreso técnico y globalización con un particular impulso-motor de la historia: Ángelus Novus. El famoso cuadro homónimo de Paul Klee se reproducía en la primera página de la publicación editada con motivo del evento. Regresaba con él el vértigo benjaminiano con connotaciones milenaristas, el viento (teológico) de la historia frente a la ortodoxia del marxismo. Chistiane Paul y Steve Dietz (quien antes citamos por su incursión en el catálogo de La conquista de la ubicuidad, exposición comisariada por Brea seis años antes), ambos comisarios de la muestra, seleccionaron obras que "nos hacen cuestionarnos si, pese a todo, aún contamos con la posibilidad de elegir, de optar, por una serie de pequeñas decisiones susceptible de influir en cómo diseñar nuestro futuro"72.

"Ya no hay Pasado ni -hasta cierto punto-Futuro"?3. Con estas palabras sacadas del texto "Una cartografía del paisaje de los media" para el catálogo de Feedforward, Benjamin Weil (comisario jefe de LABoral, cuya primera mención en el presente artículo es también referida a su aparición en el catálogo de La conquista de la ubicuidad) compartía con Brea la misma noción del mundo como no-lugar: "el mundo producido se rompe en el tiempo, deviene, se expande en timeline" ${ }^{\text {"74 }}$. El mundo como acontecimiento es protagonista en las obras de la muestra, que atrajeron un amplio número de artistas de todo el mundo: Irán, Estados Unidos, Nueva Zelanda, China, Canadá... Cuando "la Historia habría dejado de existir como punto de referencia [...] éste es un escenario en el que una vez más, para la historia de lo simbólico, tecnología y aspiración democrática pueden coincidir y favorecerse mutuamente"75. La web $2.0 \mathrm{y}$ otras aplicaciones digitales fueron tomadas como herramientas comunitarias para la ideación de prácticas de resistencia conjunta; y esto nos acaba conduciendo a la cartografía que Weil y Brea compartían acerca del paisaje de los nuevos medios y que en esta exposición se elevaba a la máxima potencia sobre la red de interconexiones donde se inscribía cada pieza.

Acercándonos ya al final del periodo de Gómez-Baeza como directora del centro, hallamos otro importante punto de inflexión con la exposición número treinta y seis que se organizó. Con el título El proceso como paradigma (LABoral, 2010), la muestra estuvo íntegramente dedicada al cuestionamiento del rol del artista contemporáneo y aludía explícitamente a las tesis de Sol LeWitt sobre la primacía del concepto en detrimento del producto final. La sala de exposiciones pasaba entonces a convertirse en un laboratorio donde el artista desarrollaba labores como investigador: "el proceso de investigación puede llegar a ser un modelo para vislumbrar nuevas formas de creación artística [...] Más que producir una serie de objetos, el

\footnotetext{
70 Benjamin Weil et al., Feedforward. El ángel de la Historia (Gijón: LABoral Centro de Arte y Creación Industrial [cat. exp.], 2009), 16.

${ }^{71}$ A lo largo de toda la producción de Brea la presencia de Benjamin se desliza de manera transversal, siendo durante los primeros años un referente absoluto para su actividad tanto teórica como curatorial. Las obras Nuevas estrategias alegóricas (1991) y Las auras frías (1991), junto a las exposiciones Iluminaciones profanas: la tarea del arte (Arteleku, 1993) y Anys 90. Distància zero (Centre d'Art Santa Mònica, 1994), no rehúyen las referencias literales al pensador alemán.

72 Weil, Feedforward, 17.

73 Weil, Feedforward, 17.

${ }^{74}$ Brea, cultura_RAM, 100.

75 Weil, Feedforward, 19.
} 
artista lleva a cabo una investigación continua organizada en torno a proyectos" ${ }^{\text {"76 }}$. Por primera vez se integraron en una muestra oficial las labores de investigación y experimentación llevadas a cabo en la Plataforma 0 de LABoral, antes referida, con el objetivo de materializar y ofrecer al público las experimentaciones del trabajo llevado a cabo en el propio centro de investigaciones.

Con todo ello y lo que antecede, llegamos a esbozar un breve bosquejo de lo que fue la puesta en marcha y consolidación de LABoral a manos de Gómez-Baeza y el resto de miembros involucrados en la primera etapa del centro (2007-2011). Finalizamos, pues, este recorrido, cediendo la voz a una de sus protagonistas desde su posición como antigua directora $\mathrm{y}$, por las implicaciones señaladas hasta el momento, colega de Brea:

[LABoral] Trataba de situarse en un "aquí y ahora" que fomentase el conocimiento y las oportunidades, en el marco de la Unión Europea y la sociedad del conocimiento. A través del artista tenemos que acercarnos a esa manera de ver el mundo. Quizá no se entendiera bien [...] Pedía una opción de hablar. LABoral supone abrir la puerta al mundo y abandonar la idea de que el arte de hoy tiene que rendir pleitesía a los valores del pasado. Hay que abrirse al futuro. Es lo que quise proponer a mi querida tierra. Pongámonos a prueba en aceptar el hoy: herramientas digitales, rol del artista, hacer pensar a las comunidades... Eso, yo creo, con todos los respetos, que no se entendió. Si hubiera vivido, tendría a Brea. Estaba ahí siempre ${ }^{77}$.

Algo no fue del todo como debiera o, efectivamente, faltó entendimiento. Quizá la ubicación del centro y su posterior condena al aislamiento fueran de la mano. Habría que determinar si ciertas contradicciones del proyecto en su conjunto están relacionadas con esa escasa presencia y repercusión de LABoral en el tejido socio-cultural de Asturias; o, por otra parte, con cierta frustración asociada a los principios proféticoteóricos de Brea para el presente digitalizado del mundo-Internet. No obstante, lo que hemos querido contar, pese a la brevedad del formato, es lo que se hizo, aquello que nos ha llegado y lo que puede aproximarnos a un proyecto institucional de gran envergadura dedicado íntegramente al arte, la ciencia, la tecnología y la innovación, a través del vínculo entre dos personalidades del pensamiento y del arte contemporáneo en el contexto español, y la genuina síntesis de teoría y praxis en torno a la cultura digital. Pese a las ineludibles tensiones institucionales de LABoral, por otra parte consustanciales a cualquier proyecto de tal envergadura, hemos primado la construcción de un relato que deje cuenta de la primera parte del proyecto, más que de una crítica en relación a las problemáticas que pueden extraerse de la narración llevada a cabo.

MIGUEL VEGA MANRIQUE es docente e investigador predoctoral en el programa de Estudios Artísticos, Literarios y de la Cultura de la UAM. Ha cursado el Grado Superior de Música (RCSMM) y estudios de filología hispánica (UNED), así como el Máster en Formación del Profesorado por la especialidad de Lengua y Literatura (UAM) y el Máster en Historia del Arte Contemporáneo y Cultura Visual (UAM/UCM/MNCARS). Durante los meses de junio de 2018 y 2019 formó parte del equipo de Mediadores Culturales del Museo Reina Sofía. También ha publicado artículos de investigación en diversas revistas académicas y participado congresos internacionales. Actualmente ejerce la docencia en la ESO y el Bachiller y sus temas de investigación más recientes giran en torno a dos ejes: las relaciones que operan entre las categorías Droga y Política con respecto a los modos de subjetivación postcapitalistas, y el lugar del deseo en la economía libidinal de las sociedades neoliberales.

Email: miguelvegam@hotmail.com

Código ORCID: https://orcid.org/0000-0002-4381-1888

${ }^{76}$ Benjamin Weil et al., El proceso como paradigma (Gijón: LABoral Centro de Arte y Creación Industrial [cat. exp.], 2010), 18-19.

77 Gómez-Baeza, entrevista. 